\title{
Teores de ácido anacárdico em pedúnculos de cajueiro Anacardium microcarpum e em oito clones de Anacardium occidentale var. nanum disponíveis no Nordeste do Brasil
}

\author{
Anacardic acid content in cashew apples from Annacardium microcarpum and eight clones of Anacardium \\ occidentale from Northeastern Brazil
}

\author{
Tânia da Silveira Agostini-Costa ${ }^{1}$ Katiane Arrais Jales ${ }^{2}$ Deborah dos Santos Garruti $^{3}$ \\ Viviane Azevedo Padilha² Jedaias Batista de Lima² ${ }^{2}$ Maria de Jesus Aguiar ${ }^{4}$ \\ João Rodrigues de Paiva ${ }^{5}$
}

\section{RESUMO}

O ácido anacárdico, composto fenólico presente em pedúnculos de caju e em algumas plantas medicinais, vem sendo associado a uma série de atividades biológicas específicas. $O$ objetivo deste trabalho foi determinar o teor deste composto em pedúnculos de cajueiro A. microcarpum e em oito clones de A. occientale var. nanum disponíveis na região Nordeste do Brasil, avaliando, também, algumas características físico-químicas e sensoriais destes pedúnculos. Os pedúnculos do clone BRS 189 apresentaram os maiores teores de ácido anacárdico. Pedúnculos da espécie Anacardium microcarpum e pedúnculos de cajueiro anão precoce, clones END 189 e 183, Embrapa 50 e 51 e CCP 09 não diferiram significativamente dos pedúnculos procedentes do clone controle, CCP 076. Pedúnculos do clone CCP 1001 apresentaram os menores teores de ácido anacárdico. As análises físico-químicas e sensoriais confirmaram evidências de que os clones CCP 09 e 1001 não são apropriados para o consumo in natura.

Palavras-chave: caju, análise sensorial, alimento funcional.

\section{ABSTRACT}

Anacardic acid, a phenolic compound present in cashew apple and in some medicinal plants, is being associated to some specific biological effects. The purpose of this work was to determine anacardic acid content in peduncles of A. microcarpum and eight clones of $A$. occidentale from Northeastern Brazil, evaluating some physical-chemical and sensory characteristics of these peduncles. Cashew apples from BRS 189 clone of early cashew tree presented the highest values of anacardic acid. Cashew apples from A. microcarpum and END 189, END 183, Embrapa 50, Embrapa 51 e CCP 09 clones of early cashew tree did not differ from control CCP 076 clone. Cashew apples from CCP 1001 clone presented the minor values of anacardic acid. Physical-chemical and sensory analyses showed evidence that CCP 09 and CCP 1001 clone are not appropriate to fresh consuption.

Key words: sensory analysis, cashew, functional food.

\section{INTRODUÇÃO}

O caju é a cultura de maior importância sócio-econômica para a região Nordeste do Brasil. A amêndoa é muito apreciada, constituindo, juntamente com o líquido da casca da castanha (LCC), o principal produto de exportação. $\mathrm{O}$ pedúnculo de aparência exótica apresenta alto teor de vitamina $\mathrm{C}$ e grande valor nutricional, entretanto, o aproveitamento ainda é insignificante em relação à quantidade da matéria-prima potencialmente disponível.

Os ácidos anacárdicos são compostos fenólicos biosintetizados a partir de ácidos graxos. Eles constituem cerca de $90 \%$ do líquido que é extraído da casca da castanha de caju, sendo que, em tais concentrações, apresentam propriedades cáusticas e irritantes (DIÓGENES et al., 1996). Entretanto, nos pedúnculos de caju, a proporção destes compostos fenólicos é muito baixa (SHOBHA et al., 1994) e suas propriedades biológicas estão merecendo atenção especial nos últimos anos. KUBO et al. (1993) demonstraram o potencial antitumor do ácido anacárdico presente no suco de caju comercial, sugerindo que o consumo contínuo do pedúnculo, assim como de seus subprodutos, durante períodos prolongados pode ser vantajoso no controle de

\footnotetext{
${ }^{1}$ Farmacêutico Bioquímico, Doutora, Pesquisadora, Embrapa Recursos Genéticos e Biotecnologia, C.P.02372, 70770-900, Brasília, DF. E-mail: tania@cenargen.embrapa.br Autor para correspondência.

${ }^{2}$ Acadêmicos do Curso de Química, bolsistas, Embrapa Agroindústria Tropical, C. P. 3761, 60511-110, Fortaleza, CE.

${ }^{3}$ Engenheiro de Alimentos, Doutora, Pesquisadora, Embrapa Agroindústria Tropical.

${ }^{4}$ Engenheiro Agrônomo, Mestre, Pesquisadora, Embrapa Agroindústria Tropical.

${ }^{5}$ Engenheiro Agrônomo, Doutor, Pesquisador, Embrapa Agroindústria Tropical.
} 
tumores. O ácido anacárdico encontrado em Ginkgo biloba foi associado ao tratamento e à prevenção de doenças cérebro-vasculares, cardiovasculares e tumorogênicas (WANG et al., 1998; ITOKAWA et al., 1987). Além dessas propriedades, sua atividade antimicrobiana e inibidora de enzimas farmacologicamente importantes vem sendo estudada (KUBO et al., 1994a; KUBO et al., 1994b; SHOBBA et al., 1994; HIMEJIMA \& KUBO, 1991; KUBO et al., 1987).

O cajueiro anão precoce (Anacardium occidentale L. var. nanum) tem sido cultivado na região Nordeste do Brasil, pois apresenta porte reduzido das plantas, facilitando a colheita manual do pedúnculo, apresenta pedúnculos com elevados teores de açúcares, menor teor de taninos oligoméricos e produtividade satisfatória (SILVA JUNIOR \& PAIVA, 1994). A espécie A. microcarpum produz pedúnculos pequenos, mas com excelente grau de doçura. Considerando-se a escassez de estudos sobre os teores de ácido anacárdico em pedúnculos de caju, o objetivo deste trabalho foi quantificar o teor destes compostos em pedúnculos de cajueiros cultivados no Nordeste do Brasil, correlacionar estes teores com alguns parâmetros meteorológicos e executar algumas análises físico-químicas e sensoriais, visando fornecer subsídios para estudos nutricionais futuros que tenham como objetivo recomendar o consumo destes pedúnculos in natura.

\section{MATERIAL E MÉTODOS}

Os clones de cajueiros avaliados neste estudo e o número de repetições variaram de acordo com a produtividade de cada safra. Durante a safra de 2001, pedúnculos da especie A. microcarpum e de clones de cajueiro anão precoce (A. occidentale) CCP 076, CCP 1001, CCP 09, BRS 189, Embrapa 50 e Embrapa 51 foram colhidos para análise de ácido anacárdico. Três lotes de pedúnculos da espécie $\boldsymbol{A}$. microcarpum (cerca de 40 unidades/lote) foram colhidos em Pacajus, Ceará (s $4^{\circ} 10^{\prime} 22^{\prime \prime}$, o $38^{\circ} 27^{\prime} 39^{\prime \prime}$ ). Três lotes de pedúnculos do clone Embrapa 50 foram colhidos em Paraipaba, Ceará (s $3^{\circ} 26^{\prime} 20^{\prime \prime}$, o $39^{\circ} 8^{\prime} 52^{\prime \prime}$ ). Para todos os demais clones, os pedúnculos foram analisados em seis lotes, três procedentes de Pacajus e três procedentes de Paraipaba.

Devido às variações climáticas ocorridas durante a safra de 2000, neste ano, não foi possível obter pedúnculos em Pacajus, com exceção de três lotes de pedúnculos do clone CCP 076. No entanto, foram empregados nas avaliações cinco lotes de pedúnculos dos clones de cajueiro anão precoce $\mathrm{CCP}$
076 e CCP 1001 e quatro lotes do clone CCP 09 procedentes de Paraipaba. Foram analisados, ainda, três lotes dos clones de cajueiro anão precoce CCP 076, END 189, END 183 e BRS 189 procedentes da Fazenda Pimenteira, pertencente ao grupo CIONE, situada em Aracati, CE (s 4 33' 43", o $37^{\circ} 46^{\prime} 11^{\prime \prime}$ ).

Em ambas as safras e nas diferentes procedências, os pedúnculos do clone CCP 076 foram empregados como controle. Esse clone, por apresentar excelente produtividade e pedúnculos de ótima qualidade para consumo in natura, é, atualmente, o mais difundido. Cada lote de pedúnculo de caju foi obtido em diferentes semanas, durante cada safra. Os pedúnculos foram colhidos aleatoriamente pela manhã (cerca de 40 unidades/lote), em estado de maturação apropriado para o consumo in natura e transportados em caixas apropriadas. Cerca de vinte unidades de pedúnculos foram selecionados e quarteados longitudinalmente. As primeiras frações foram agrupadas, constituindo uma contra-prova, que foi congelada a $-20^{\circ} \mathrm{C}$ e utilizada de acordo com a necessidade. As segundas frações foram homogeneizadas em liquidificador. Destas frações homogeneizadas, foram retiradas três amostras que serviram como repetições e foram submetidas às análises.

A obtenção do padrão de ácido anacárdico e a determinação deste composto em pedúnculos de caju foi feita conforme AGOSTINI-COSTA et al. (2003). Para a obtenção do padrão, o ácido anacárdico foi extraído com hexano a partir das cascas de castanhas de caju, e purificado em coluna de sílica acidificada. O padrão apresentou-se puro quando identificado por cromatografia em camada delgada, por varredura espectral no ultravioleta e por análises de ressonância magnética nuclear de ${ }^{1} \mathrm{H}, 500 \mathrm{MHz}$ e de ${ }^{13} \mathrm{C}, 125 \mathrm{MHz}$ (Brucker, Avance DRX 500). A extração analítica do ácido anacárdico foi feita por partição com clorofórmio, metanol e água. O extrato foi purificado em mini-coluna de sílica e o ácido anacárdico, diluído em hexano, foi quantificado a $320 \mathrm{~nm}$ em espectrofotômetro de varredura espectral ultravioleta-visível (Varian, modelo Cary 50).

As determinações de açúcares redutores, acidez total titulável, pH e sólidos solúveis totais ( ${ }^{\circ}$ Brix) foram feitas de acordo com os métodos analíticos do INSTITUTO ADOLFO LUTZ (1985).

A análise sensorial foi realizada com pedúnculos de quatro clones de cajueiro anão precoce cultivados tanto em Pacajus como em Paraipaba, e também da espécie $\boldsymbol{A}$. microcarpum cultivados em Pacajus. Uma equipe composta de 13 julgadores selecionados e treinados (GARRUTI et al., 2002) avaliou cada amostra, em três repetições, quanto à 
Impressão Global. Foi utilizada uma escala não estruturada de $9 \mathrm{~cm}$ ancorada nos extremos com os termos "muito ruim" e "muito boa".

Visando à exploração dos resultados obtidos, parâmetros meteorológicos, como precipitação, temperatura e umidade relativa, ocorridos nas Estações Experimentais da Embrapa em Paraipaba e Pacajus durante as safras de 2000 e 2001, foram checados para avaliar a correlação dos mesmos com os teores de ácido anacárdico obtidos. Foram consideradas, separadamente, as médias das repetições dos clones CCP 076, CCP 1001 e CCP 09. Os períodos cujos parâmetros meteorológicos foram avaliados corresponderam: i) às faixas entre as quartas $\mathrm{e}$ quintas semanas que antecederam as colheitas de cada lote de pedúnculos de caju (estimativa da quinzena referente ao metabolismo rápido do ácido anacárdico segundo SHOBHA et al.,1994); ii) às faixas entre as quartas e oitavas semanas que antecederam as colheitas de cada lote (estimativa do período médio referente aos 35 dias de desenvolvimento dos pedúnculos de caju, desde a polinização até o final do metabolismo rápido do ácido anacárdico).

A análise estatística dos resultados foi realizada utilizando-se o programa SAS (versão 8e, Cary, NC). Os resultados dos teores de ácido anacárdico obtidos em cada ano (2000 e 2001) foram submetidos separadamente à Análise de Variância (ANOVA) e Teste de Tukey em nível de 5\% de probabilidade de erro para comparação entre as médias. Como as variações das repetições foram de origem analítica e inferiores a 5\%, foi calculada uma média das três repetições que serviram para as análises estatísticas de cada lote (uma média por lote). As comparações foram feitas entre as médias dos diferentes clones analisados e do controle, CCP 076, que apresenta excelente produtividade, é o clone mais difundido e, por isso, foi facilmente obtido nas duas safras e nas diferentes origens. Para avaliar o efeito do ano, foram consideradas as médias das repetições dos clones CCP 076, CCP 1001 e CCP 09. Os resultados da análise sensorial foram submetidos à Análise de Variância (ANOVA) e Teste de Tukey em nível de 5\% de significância para comparação de médias. As análises das possíveis correlações entre os teores de ácido anacárdico e os parâmetros meteorológicos obtidos foram feitas empregando-se a análise de Correlação de Pearson, de acordo com BOX et al. (1978).

\section{RESULTADOS E DISCUSSÕES}

Os pedúnculos de cajueiro anão precoce clone BRS 189 apresentaram os maiores valores médios de ácido anacárdico (Figura 1). A proporção de ácido anacárdico em pedúnculo de caju aumenta rapidamente durante o desenvolvimento, atingindo cerca de $1,5 \%$

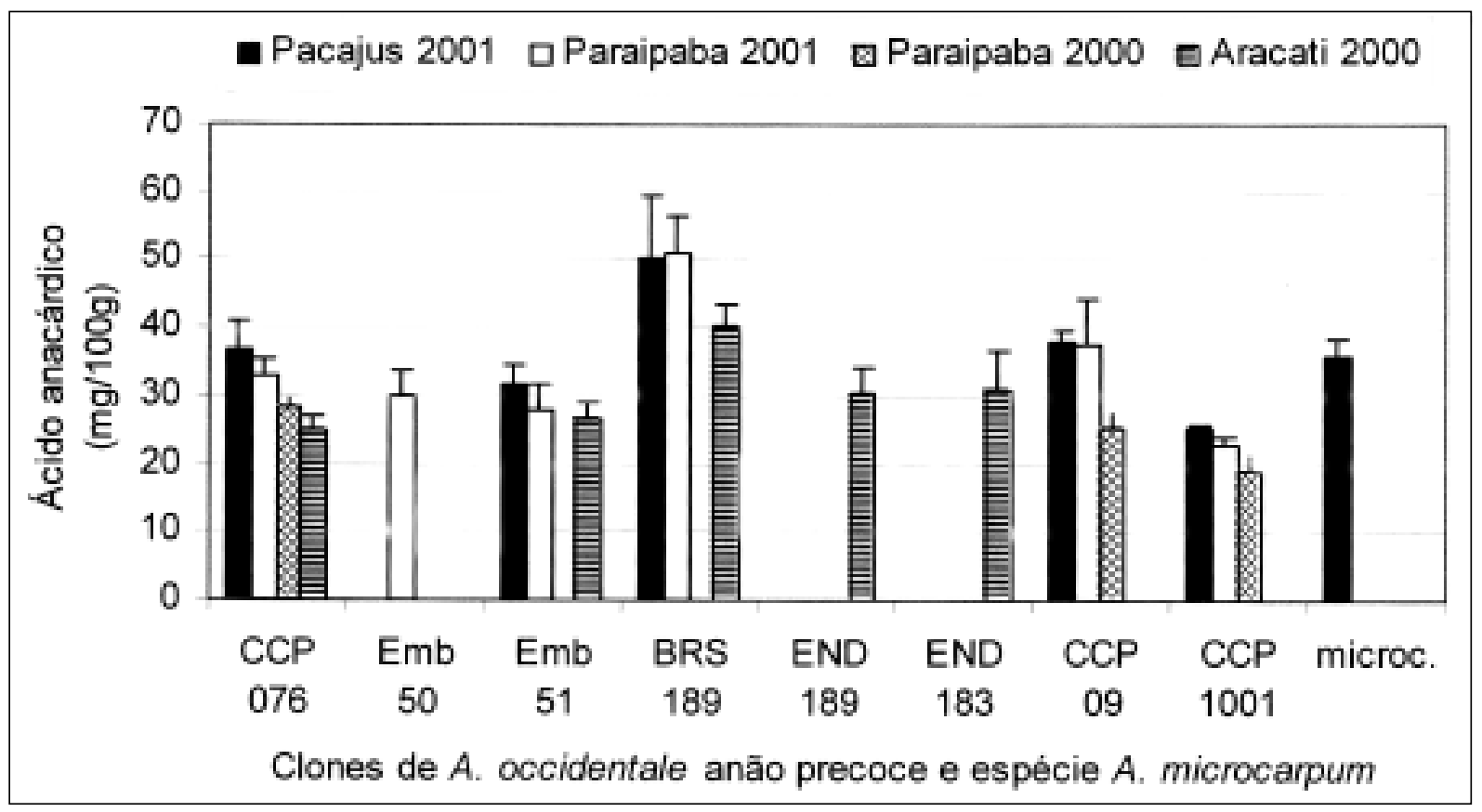

Figura 1 - Teores de ácido anacárdico em pedúnculos de $\boldsymbol{A}$. microcarpum (microc.) e em pedúnculos de oito clones de cajueiro $\boldsymbol{A}$. occidentale anão precoce procedentes de Pacajus, Paraipaba e Aracati, CE, safras 2001 e 2000; clone CCP 076 = controle: cada barra corresponde à média de três a cinco lotes analisados em três repetições. 
do peso do pedúnculo na terceira semana após a polinização e, praticamente, desaparece durante as duas semanas subseqüentes (SHOBHA et al., 1994). Segundo estes autores, o acúmulo rápido de açúcar e água no pedúnculo acompanha a interrupção da síntese de ácido anacárdico. Os baixos teores deste composto não foram quantificados por SHOBHA et al. (1994) em pedúnculos maduros.

Em 2001, a média de ácido anacárdico encontrada nos pedúnculos BRS 189 de Paraipaba $(51,0 \mathrm{mg} / 100 \mathrm{~g})$ diferiu significativamente da média encontrada para o clone controle CCP 076 do mesmo local $(33,0 \mathrm{mg} / 100 \mathrm{~g})$. Os pedúnculos do clone BRS 189 , lançado recentemente para o plantio comercial na região Nordeste do Brasil, apresentaram boa impressão global nos provadores para o consumo in natura, não diferindo do clone CCP 076 (Tabela 1). A qualidade sensorial do pedúnculo de caju para consumo in natura está relacionada, principalmente, à doçura (PAIVA et al., 1998). Os principais componentes da doçura, sólidos solúveis totais (SST) e acidez, do pedúnculo BRS 189 (Tabela 2), também, não diferiram em relação ao controle, o que justifica a boa aceitação comercial destes pedúnculos.

Os teores de ácido anacárdico (Figura 1) dos pedúnculos da espécie $\boldsymbol{A}$. microcarpum (Pacajus, 2001) e dos clones de cajueiro anão precoce, END 189 (Aracati, 2000); END 183 (Aracati, 2000); Embrapa 50 (Paraipaba, 2001); Embrapa 51 (Pacajus e Paraipaba, 2001 e Aracati, 2000) e CCP 09 (Pacajus e Paraipaba, 2001 e Paraipaba 2000) não diferiram significativamente, em nível de $5 \%$ de probabilidade de erro, daqueles provenientes do clone controle, CCP 076 cultivado no mesmo local e na mesma safra dos demais clones. Segundo SILVA JUNIOR \& PAIVA (1994), os pedúnculos do clone CCP 076 apresentaram excelente grau de doçura quando comparados ao clone CCP 09. No presente trabalho, os pedúnculos do clone CCP 09 apresentaram baixo teor de SST e/ou açúcares redutores (Tabela 2). Em trabalho paralelo, realizado com os mesmos pedúnculos, observou-se elevado teor

Tabela 1 - Análise sensorial de pedúnculos de clones de cajueiro $\boldsymbol{A}$. occidentale var. nanum e cajueiro A. microcarpum.

\begin{tabular}{ll}
\hline Clone & Impressão global $^{1}$ \\
\hline CCP 076 (controle) & $5,95 \mathrm{a}$ \\
BRS 189 & $5,49 \mathrm{ab}$ \\
CCP 1001 & $5,38 \mathrm{bc}$ \\
Microcarpum & $5,32 \mathrm{bc}$ \\
CCP 09 & $4,92 \mathrm{c}$ \\
\hline
\end{tabular}

${ }^{1}$ Valores com letras diferentes apresentam diferença significativa em nível de $5 \%$. de taninos adstringentes. Estes dois parâmetros justificam a baixa aceitação do pedúnculo deste clone para o consumo in natura. Na análise sensorial, os pedúnculos desse clone obtiveram a média mais baixa que diferiu do controle CCP 076 (Tabela 1).

Os pedúnculos da espécie $A$. microcarpum são popularmente referidos como de excelente sabor e livre de adstringência (popularmente chamada de "travo" ou "ranço"), entretanto, os teores de ácidos anacárdicos destes pedúnculos não diferiram do controle. O elevado teor de açúcar e SST destes pedúnculos (Tabela 2), com repercussão na doçura, aparentemente, é responsável pela boa aceitação sensorial popularmente observada. Entretanto, o tamanho reduzido destes pedúnculos ainda é um obstáculo para o mercado, cujos consumidores preferem pedúnculos com peso variando entre $100 \mathrm{e}$ 140g (PAIVA et al., 1998). Esse fato foi confirmado, neste trabalho, pela baixa impressão global observada para os pedúnculos deste clone, que diferiu da impressão global do controle, CCP 076 (Tabela 1). Apesar do alto grau de doçura e baixa adstringência desse material (GARRUTI et al., 2002), aspectos relacionados a sua aparência prejudicaram a avaliação global que o provador fez da amostra.

Os pedúnculos do clone CCP 1001 apresentaram os menores teores de ácido anacárdico (Figura 1), que diferiram significativamente dos valores encontrados para o clone controle CCP 076 de ambos os locais em 2001. Estes pedúnculos possuem baixo teor de açúcar (Tabela 2) e apresentaram impressão global inferior ao clone controle (Tabela 1).

Nenhuma referência sobre o teor de ácido anacárdico determinado em pedúnculos maduros foi encontrada, sendo que o suco de caju comercial apresentou $0,98-1,5 \mathrm{mg}^{100 \mathrm{~mL}^{-1}}$ (LIMA, 1999) e o suco liofilizado apresentou 50mg 100 $\mathrm{g}^{-1}$ (KUBO et al., 1986). Considerando-se a característica lipossolúvel do ácido anacárdico, acredita-se que, durante a extração do suco, grande parte do ácido anacárdico permaneça adsorvida no bagaço do pedúnculo.

O local de avaliação dos clones, onde foram colhidos os pedúnculos para análise, não influenciou nos teores de ácido anacárdico. Entretanto, o ano de colheita apresentou efeito significativo nos teores de pedúnculos dos clones CCP 09 e CCP 076, quando considerados os clones CCP 09, CCP 1001 e CCP 076 procedentes de Paraipaba e de Pacajus analisados nos anos 2000 e 2001. A elevada precipitação pluvial observada no ano 2000 foi o principal agente climático diferenciador observado, quando foram verificados os menores teores de ácido anacárdico em pedúnculo de caju. No período compreendido entre julho e novembro 
Tabela 2 - Análises físico-químicas de pedúnculos de clones de cajueiro A. occidentale var. nanum e cajueiro A. microcarpum procedentes de Pacajus e Paraipaba, CE.

\begin{tabular}{lcccccccc}
\hline \multicolumn{1}{c}{ Determinação } & & \multicolumn{3}{c}{ Pacajus* } & & & \multicolumn{2}{c}{ Paraipaba* } \\
& CCP 076 & CCP 09 & BRS 189 & A. microcarpum & CCP 076 & CCP 09 & BRS 189 & CCP 1001 \\
\hline pH & $4,46 \mathrm{ab}$ & $4,36 \mathrm{ab}$ & $4,36 \mathrm{ab}$ & $4,66 \mathrm{a}$ & $4,37 \mathrm{ab}$ & $4,41 \mathrm{ab}$ & $4,27 \mathrm{~b}$ & $4,27 \mathrm{~b}$ \\
SST $^{1}$ & $12,2 \mathrm{ab}$ & $11,3 \mathrm{ab}$ & $12,0 \mathrm{ab}$ & $13,5 \mathrm{a}$ & $10,8 \mathrm{~b}$ & $10,9 \mathrm{~b}$ & $11,7 \mathrm{ab}$ & $10,7 \mathrm{~b}$ \\
ATT $^{2}$ & $0,29 \mathrm{ab}$ & $0,25 \mathrm{~b}$ & $0,32 \mathrm{ab}$ & $0,30 \mathrm{ab}$ & $0,27 \mathrm{ab}$ & $0,24 \mathrm{~b}$ & $0,34 \mathrm{ab}$ & $0,37 \mathrm{a}$ \\
Açucares e redutores $^{3}$ & $10,49 \mathrm{ab}$ & $10,53 \mathrm{ab}$ & $9,33 \mathrm{ab}$ & $11,55 \mathrm{a}$ & $10,38 \mathrm{ab}$ & $9,13 \mathrm{ab}$ & $10,42 \mathrm{ab}$ & $8,55 \mathrm{~b}$ \\
\hline
\end{tabular}

${ }^{1}$ Sólidos solúveis totais ( ${ }^{\circ}$ Brix); ${ }^{2}$ acidez total titulável (g de ácido cítrico / $\left.100 \mathrm{~g}\right) ;{ }^{3}(\%) ; *$ valores na mesma linha com letras diferentes apresentam diferença significativa em nível de $5 \%$..

de 2000, a precipitação atingiu 203 mm em Pacajus e $166 \mathrm{~mm}$ em Paraipaba. No mesmo período do ano 2001, a precipitação atingiu apenas $31,4 \mathrm{~mm}$ em Pacajus e 29,4mm em Paraipaba.

A umidade relativa apresentou correlação negativa com os teores de ácido anacárdico dos pedúnculos de todos os clones considerados: CP 09, CP076 e CP 1001 (Tabela 3). Este efeito foi significativo quando avaliados os dois períodos: período associado ao metabolismo rápido do ácido anacárdico (15 dias) e período médio estimado de desenvolvimento do pedúnculo desde a polinização até o final do metabolismo do ácido anacárdico (35 dias).
A precipitação pluvial (Tabela 3) apresentou correlação negativa com os teores de ácido anacárdico dos pedúnculos CP 1001 e CP 09. Para os pedúnculos do clone CP 1001, a precipitação apresentou efeito nos dois períodos avaliados. Para o CP 09, o efeito foi observado apenas quando considerado o período estimado desde a polinização até o final do metabolismo do ácido anacárdico. Os teores de ácido anacárdico dos pedúnculos CP 076 não apresentaram correlação significativa com a precipitação pluviométrica.

A temperatura ambiente foi correlacionada apenas com os teores de ácido anacárdico dos pedúnculos

Tabela 3. - Matriz de correlação de Pearson entre teores de ácido anacárdico em pedúnculos de clones de cajueiro anão precoce e parâmetros meteorológicos correspondentes

\begin{tabular}{|c|c|c|c|c|c|c|c|}
\hline Clone & Parâmetro & Acido anacárdico & Precipitação ${ }^{1}$ & Temperatura $^{1}$ & Umidade relativa $^{1}$ & Precipitação ${ }^{2}$ & $\begin{array}{l}\text { Umidade } \\
\text { relativa }^{2}\end{array}$ \\
\hline \multirow{6}{*}{ ССР 09} & Ac. anacárdico & 1,00000 & $-0,27393$ & $0,70557 *$ & $-0,73154 *$ & $-0,72095^{*}$ & $-0,65217 *$ \\
\hline & Precipitação $^{1}$ & & 1,00000 & $-0,62994^{*}$ & $0,67079 *$ & $0,62787 *$ & 0,46330 \\
\hline & Temperatura $^{1}$ & & & 1,00000 & $-0,84209 *$ & $-0,78385^{*}$ & $-0,57960 *$ \\
\hline & U. relativa ${ }^{1}$ & & & & 1,00000 & $0,85909 *$ & $0,68139 *$ \\
\hline & Precipitação ${ }^{2}$ & & & & & 1,00000 & $0,69331 *$ \\
\hline & U. relativa ${ }^{2}$ & & & & & & 1,00000 \\
\hline \multirow{6}{*}{ ССР 076} & Ac. anacárdico & 1,00000 & $-0,25026$ & 0,00024 & $-0,52981 *$ & $-0,39328$ & $-0,52736^{*}$ \\
\hline & Precipitação $^{1}$ & & 1,00000 & $-0,12645$ & $0,76285^{*}$ & $0,76703 *$ & $0,55821 *$ \\
\hline & Temperatura $^{1}$ & & & 1,00000 & $-0,42501$ & $-0,49087$ & $-0,68311 *$ \\
\hline & U. relativa ${ }^{1}$ & & & & 1,00000 & $0,85587 *$ & $0,86265^{*}$ \\
\hline & Precipitação ${ }^{2}$ & & & & & 1,00000 & $0,82995^{*}$ \\
\hline & U. relativa ${ }^{2}$ & & & & & & 1,00000 \\
\hline \multirow{6}{*}{ ССР 1001} & Ac. anacárdico & 1,00000 & $-0,58103^{*}$ & $-0,19501$ & $-0,63398 *$ & $-0,57747 *$ & $-0,76803^{*}$ \\
\hline & Precipitação $^{1}$ & & 1,00000 & $-0,34695$ & 0,38559 & $0,58476^{*}$ & $0,81585^{*}$ \\
\hline & Temperatura $^{1}$ & & & 1,00000 & $-0,05189$ & $-0,18661$ & $-0,24180$ \\
\hline & U. relativa ${ }^{1}$ & & & & 1,00000 & 0,27669 & $0,73550 *$ \\
\hline & Precipitação ${ }^{2}$ & & & & & 1,00000 & 0,47456 \\
\hline & U. relativa ${ }^{2}$ & & & & & & 1,00000 \\
\hline
\end{tabular}

${ }^{1}$ Período de 35 dias entre as quartas e quintas semanas que antecederam as colheitas de cada lote; ${ }^{2}$ Referente às primeiras 5 semanas de desenvolvimento dos pedúnculos; *significativo a $5 \% ; \mathrm{N}=12$.

Ciência Rural, v.34, n.4, jul-ago, 2004. 
do clone CCP 09. Entretanto, provavelmente, este efeito apresentou influência da alta correlação observada entre temperatura/precipitação e umidade relativa. A umidade relativa foi o parâmetro meteorológico de efeito geral mais pronunciado nos teores de ácido anacárdico dos três clones considerados. Além da precipitação, outros fatores como relevo, tipo de solo, vegetação e temperatura ambiente também interferem na umidade relativa. Curiosamente, na região do Planalto Central do Brasil, onde a umidade relativa é muito baixa, podendo atingir a marca de $10 \%$ entre os meses de julho e setembro, ocorre um atraso na produção dos pedúnculos de caju, em relação à safra do nordeste. Os pequenos pedúnculos produzidos nesta região são referidos como "pouco apropriados para o consumo in natura", devido ao elevado "ranço".

As propriedades biológicas do ácido anacárdico fazem do pseudofruto do caju uma fonte promissora de compostos bioativos, cujo aproveitamento poderá vir a ser estimulado. Estudos futuros sobre a ingestão dietética do ácido anacárdico, nas concentrações encontradas nos pedúnculos de caju analisados, podem abrir caminho para a confirmação da atuação deste composto na prevenção de doenças crônico-degenerativas. Estas propriedades poderão inserir perspectivas para exploração do pedúnculo de caju como alimento funcional, evitando-se as perdas ocorridas, reforçando-se o valor nutricional na alimentação da população em geral efavorecendoo desenvolvimentoeconômicoe social, principalmente, na região Nordeste do Brasil.

\section{CONCLUSÕES}

Os pedúnculos de cajueiros anões precoces clone BRS 189 apresentaram os maiores teores de ácido anacárdico. Pedúnculos do clone CCP 1001 apresentaram os menores teores deste ácido fenólico. As análises físico-químicas e sensoriais confirmaram evidências de que os clones CCP 09 e CCP 1001 não são apropriados para o consumo in natura.

\section{AGRADECIMENTOS}

Ao Banco do Nordeste do Brasil pelo suporte financeiro e ao CENAUREM pelas análises de ressonância magnética nuclear. Ao Dr. Guy Capdeville pelas sugestões oferecidas.

\section{REFERÊNCIAS BIBLIOGRÁFICAS}

AGOSTINI-COSTA, T. S. et al. Determinação de ácido anacárdico em pedúnculos de caju. Revista Brasileira de Plantas Medicinais, v.5, n.2, p.77-81, 2003.

BOX, G.E.P.; HUNTER, W.G.; HUNTER, J.S. Statistics for experimenters. New York : John Wiley \& Sons, 1978. $653 \mathrm{p}$.
DIOGENES, M.J.N.; MARAIS, S.M.; CARVALHO, F.F. Contact dermatitis among cashew nut workers. Contact Dermatitis, v.35, p.114-115, 1996.

GARRUTI, D.S. et al. Caracterização sensorial de pedúnculos de clones de cajueiro anão-precoce cultivados sob sequeiro e irrigação, para consumo in natura. In: CONGRESSO BRASILEIRO DE CIÊNCIA E TECNOLOGIA DE Alimentos, 2002, Porto Alegre, RS. Anais... Porto Alegre: SBCTA, 2002. p.1898-1901.

HIMEJIMA, M.; KUBO, I. Antibacterial agents from the cashew Anacardium occidentale (Anacardiaceae) nut shell oil. Journal of Agriculture and Food Chemistry, v.39, p.418-421, 1991.

INSTITUTO ADOLFO LUTZ. Métodos químicos e físicos para análise de alimentos. São Paulo : Varela, 1985. 533p.

ITOKAWA, Y. et al. Antitumor principles from Ginkgo biloba L. Chemical Pharmaceutical Bulletin, v.35, p.16-20, 1987.

KUBO I.; KOMATSU S.; OCHI M. Mulluscocicides from the cashew (Anacardium occidentale) and their large-scale isolation. Journal of Agriculture and Food Chemistry, v.34, p.970-973, 1986.

KUBO, I. et al. Prostaglandin syntetase inhibitors from the African medicinal plant Ozoroa mucronata. Chemistry Letters, v.63, p.1101-1104, 1987.

KUBO, I. et al. Antitumor agents from the cashew (Annacardium occidentale) apple juice. Journal of Agriculture and Food Chemistry, v.4, p.1012-1015, 1993.

KUBO, I.; KINST-HORI, I.; YOKOKAWA, Y. Tyrosinase inhibitors from Anacardium occidentale fruits. Journal of Natural Products, v.57, p.545-551, 1994a.

KUBO, I.; MUROI, H.; KUBO, A. Naturally occurring antiacne agents. Journal of Natural Products, v.57, p.9$17,1994 b$.

LIMA, C.A. Estudo dos ácidos anacárdicos do óleo da casca de castanha de caju (CNSL) (Anacardium occidentale L) dos clones de cajueiro anão precoce CCP 076 e CCP 09 em cinco estágios de maturação. 1999. 184f. Tese (Doutorado em Ciência de Alimentos) - Faculdade de Engenharia de Alimentos, Universidade Estadual de Campinas.

PAIVA, J.R. et al. Produção e qualidade de pedúnculos de clones de cajueiro anão precoce sob cultivo irrigado. Fortaleza : EMBRAPA, CNPAT, 1998. 5p. (Comunicado Técnico, 19).

SHOBHA, S.V.; RAMADOSS, C.S.; RAVINDRANATH, B. Inhibition of soybean lipoxygenase-1 by anacardic acids cardols and cardanols. Journal of Natural Products, v.57, p.1755-1757, 1994.

SILVA JUNiOR, A.; PAIVA, F.F.A. Estudo físico e físico-químico de clones de cajueiros anão precoce. Fortaleza : EPACE, 1994. 5p. (Boletim de pesquisa, 23).

WANG, D. et al. Inhibitory activity of unsaturated fatty acids and anacardic acids toward soluble tissue factor-factor VIIa complex. Journal of Natural Products, v.62, p.1352-1355, 1998. 